\title{
Capsule Commentary on Gaither et al., the Association Between Receipt of Guideline-Concordant Long-Term Opioid Therapy and All-Cause Mortality
}

\author{
Gary M. Franklin, MD, MPH \\ Seattle, WA, USA. \\ J Gen Intern Med 31(5):534 \\ DOI: $10.1007 / \mathrm{s} 11606-016-3625-2$ \\ (c) Society of General Internal Medicine 2016
}

Research Professor, Departments of Environmental and Occupational Health Sciences, Neurology, and Health Services, University of Washington,

$\mathrm{T}$ he article by Gaither et al. ${ }^{1}$ in this issue of JGIM is an important study. First, and most importantly, it properly concludes that initiating long-acting opioids in patients at increased risk for an overdose event or other serious harms related to co-prescription of benzodiazepines or in those with untreated substance use disorder is not a good idea. While the language used is to be cautious, stronger language in recent state guidelines suggests not using opioids in these circumstances. ${ }^{2}$

Second, the authors find that use of any psychotherapeutic or physical rehabilitative treatment is associated with reduced all-cause mortality, and emphasize in the discussion and references that multimodal care for chronic pain is essential. For many non-specific pain disorders, such as low back pain, headaches, and fibromyalgia, the evidence that chronic opioid use is effective long term is non-existent. ${ }^{3}$ This makes the use of alternatives all that more attractive, considering that the evidence for dose-related serious harm is much stronger than the evidence of longer-term effectiveness. ${ }^{4}$

Larger, more potentially integrated health systems such as the Veteran's Administration may have greater capacity to more adequately deliver multimodal care. Both graded exercise and cognitive-behavioral therapy have very strong evidence bases for use in chronic pain. ${ }^{2}$ If anything, insurers' payment for these types of treatment may have substantially declined early on in the epoch of dramatically increasing opioid prescribing for chronic, non-cancer pain. The thinking may have gone along the lines of, "Wow, we can pay for a few prescriptions and not have to bother with all that biobehavioral stuff!" But we have belatedly recognized that the worst man-made epidemic in modern medical history related to the over-prescription of opioids is very tough to reverse. And the human and financial costs of this epidemic, including dramatically increasing mortality amongst middle-aged whites, ${ }^{5}$ should be a clarion call to deliver more effective alternatives to opioids.

The highest priority should be to prevent the next cohort of our citizens getting into deep trouble from inappropriate use of opioids. This should begin with much more prudent use of opioids, even for acute pain. Getting a wisdom tooth extracted? Make sure the dentist only gives you a few short-acting opioid pills, so there's nothing left for the kids in the medicine cabinet.

Corresponding Author: Gary M. Franklin, MD, MPH; Research Professor, Departments of Environmental and Occupational Health Sciences, Neurology, and Health ServicesUniversity of Washington, Seattle, WA, USA (e-mail: meddir@uw.edu).

\section{Compliance with Ethical Standards:}

Conflict of Interest: The author has no conflict with any material in this manuscript.

\section{REFERENCES}

1. Gaither JR, Goulet JL. Becker WC, et al. The association between receipt of guideline-concordant long-term opioid therapy and all-cause mortality. J Gen Intern Med. DOI: 10.1007/s11606-015-3571-4

2. Washington Agency Medical director's Group. Interagency Guideline on Prescribing Opioids for Pain. June, 2015. URL: http://www. agencymeddirectors.wa.gov/Files /2015AMDGOpioidGuideline.pdf. Accessed 12/24/2015.

3. Franklin GM. Opioids for chronic, non-cancer pain. A position paper of the American Academy of Neurology. Neurology. 2014;83:1277-1284.

4. Chou R, Turner JA, Devine EB, et al. The effectiveness and risks of longterm opioid therapy for chronic pain: A systematic review for a National Institutes of Health Pathways to Prevention workshop. Ann Int Med. 2015;162:276-286.

5. Case A, Deaton A. Rising morbidity and mortality in midlife among white, nonHispanic Americans in the 21st century. Proc National Acad Sci. URL: http:// www.pnas.org/content/112/49/15078.full.pdf. Accessed 12/24/2015.

This comment refers to the article available at: http://dx.doi.org/10.1007/ s11606-015-3571-4.

Published online February 16, 2016 